\title{
CORROSION IMPACT ANALYSIS ON RESIDUAL LIFE OF STRUCTURE USING CATHODIC TECHNIQUE AND ALGOR SIMULATION SOFTWARE
}

\author{
Chittaranjan Birabar NAYAK ${ }^{*}$, Nivedita Sunil THROAT ${ }^{2}$, Sunil Bhimrao THAKARE \\ ${ }^{1}$ Dr. D. Y.Patil Vidya Pratishthan Society's Dr. D. Y. Patil Institute of Technology, \\ Sant Tukaram Nagar, Pimpri, Pune 411 018, Maharashtra, India \\ ${ }^{2}$ Vidya Pratishthan's Kamalnayan Bajaj College of Engineering \& Technology, \\ Baramati, Pune 413133, Maharashtra, India \\ ${ }^{3}$ Anantrao Pawar College of Engineering \& Research, Laxminagar, Parvati, Pune 411009, Maharashtra, India
}

Received 23 November 2017; accepted 06 March 2018

\begin{abstract}
Damage to the reinforced concrete structure is mainly occurring because of two reasons either due to end of service life or due to load exceeds beyond structural capacity. Along with these two reasons degradation of material property is the one more major factor which causes the risk of failure. A concrete structure constructed in an aqueous environment get exposed to the corrosion process. Consequently, this causes the generation of crack, fragilization, a decrease of bond strength between reinforcement and concrete. All these factors affection static and dynamic behavior of concrete structure reducing the service life of an affected area. Whereas service life carries the major role in the economy of a concrete structure that is why various methods have been developed in the second half of the $20^{\text {th }}$ century to find out the residual life of the structure. In this proposed work, a non-destructive technique is used to predict the residual life of reinforced concrete beams having different cracking levels, as results of steel reinforcement corrosion, considering the variation produced in the dynamic behavior, through the variation of the first natural vibration frequency. Whereas to accelerate the corrosion process, impress current technique is used in which a current is externally applied to induce corrosion in reinforcement and then crack widths and vibration natural frequencies were measured. A numerical model is proposed with the help of FEM based Auto desk Algor simulation software to predict attack penetration depth. At the end, the paper is concluded by giving an effect of "water to cement ratio" and "cover to diameter ratio" on the initiation and propagation of corrosion and residual life of corroded beam specimen is graphically represented.
\end{abstract}

Keywords: reinforced concrete, corrosion, residual life, non-destructive testing.

\section{Introduction}

In the twenty-first century, all infrastructures like residential buildings, public buildings, and commercial buildings all reinforce concrete or steel structure. Failure of reinforced concrete structure takes place due to two important reasons, either load over a structure exceeds load carrying capacity or serviceability criteria of structure get expired. Along with these two significant reasons for structural failures, material property degradation is another foremost reason for the collapse of reinforced concrete structures. Material property degradation consequently results in to change the physical and mechanical behavior of the structure and this mainly occurs due to environmental conditions. A reinforced concrete structure constructed in marine environment gets affected due to the salty nature of the atmosphere and results in reinforcement corrosion.
Corroded members of affected structure show initiation of crack, fragilization, concrete-steel bond loss and risk of failure or even collapse may arise that could have a major socioeconomic impact (Torres-Luque, Bastidas-Arteaga, Schoefs, Sanchez-Silva, \& Osma, 2014).

Corrosion is the gradual destruction of metal by chemical and electrochemical reaction with an aqueous environment. During the electrochemical process of corrosion, a formation of rust takes place which exerts radial pressure on the surrounding concrete subjecting it to axial tension which induces cracking (Khan, Franois, \& Castel, 2014; Capozucca, 1995). The width of these cracks depends on the quality and the cover thickness of the concrete, along with the spatial distribution of the reinforcement and stress state to which the reinforcing steel

\footnotetext{
${ }^{\star}$ Corresponding author. E-mail: cbnnayak@gmail.com
} 
is subjected (Alonso, Andradel, Rodriguez, \& Dies, 1998; Aveldano \& Ortega, 2009). Formation and propagation of crack lead into the reduction of the reinforced concrete element cross section, which diminishes the effective moment of inertia, influencing the elements dynamic and static behavior (Ortega \& Robles, 2016).

In this work, the experimental-numerical methodology is presented to estimate the end of the functional service life. Where service life can be defined as the period of life in which structural resistance withstand the design structural load. Structural life is getting affected by the environmental condition. The residual life of the structure can define as the life remains after spending a certain period of structural service life. Here in this work dynamic parameter as a first natural frequency taken into consideration to analyze the behavior of structures before and after corrosion and for this beam specimens are selected (Razak \& Choi, 2001). Corrosion is an electrochemical process even in a severe corrosive environment, it takes significant time to initiate and propagate. Therefore, to accelerate corrosion in the shortest period of time accelerate test like impressed current technique is utilized. Concrete mix design is done in three different water to cement ratio and two different covers to diameter ratio of reinforcement to study its effect on the initiation and propagation time of corrosion. Variation of natural frequency at different damaged level is simulated in Autodesk Algor simulation software and attack penetration depth is found using Faraday's law of electrochemistry. The proposed method quantifies residual life of the structure in non-destructive approach without disturbing serviceability of study beam.

After the several types of research on corrosion of reinforcement, it has shown that corrosion not only effects on the mechanical or physical property of the structure but it also reduces the service life of an affected structure. Reinforcement corrosion influences load carrying capacity, the overall strength of the structure reduces and serviceability criteria get disturbed so that structural safety comes in danger (Ortega \& Robles, 2016). All the process of corrosion and its influence on service life shows that there is a need to develop the non-destructive method to analyze the state of structural deterioration, a method which evaluates the structure without separating its integrated part for performing testing. There are several methods available under the nondestructive technique of corrosion monitoring which monitor and find corrosion affected area of the structure (Ahmad, 2003).

Several researchers work on the residual life structure by considering either mechanical behavior or physical property. In case of physical property, researcher relates the penetration of chlorides and /or carbonation to establish a limit for the service life after the reinforcement depassivation and other studies take under consideration the structural behavior of the corrosion affected element. In this way, it established the ultimate load carrying capacity turn into structural safety coefficient, which further helps to determine the residual life of the structure.
W. Zhu and R. Francois (2014) present the effect of chloride corrosion on the reinforcement bars and the influence of corrosion on the residual mechanical performance of a corroded beam at the age of 26 years by loading it in a three-point loading system until failure. X. Wang, W. Zhang, X. Gu and H. Dai (2013) used rebar specimens under carbonation induced corrosion and chloride-induced contamination and three-dimensional (3D) laser scanning technique was then employed to build virtual models of corroded bars with the aid of a computer to analyses area loss of corroded reinforcement. N. Palumbo (1991) gives the results of an experimental research program carried out at McGill University dealing with accelerated electrochemical corrosion testing of reinforced concrete. The main objective of this study is to determine the importance and influence of the depth of the concrete cover thickness on the rate of corrosion of steel reinforcement and thereby, on the resistance of concrete. N. Ortega and S. Robles (2016) presents results from an experimental study monitoring the behavior of reinforced concrete beams with different reinforcement positions (stirrups and main longitudinal reinforcement) that have undergone a galvanostatic process of accelerated corrosion. R. Capozucca and M. Nilde Cerri (2003) deal with the response of RC beams damaged by the reinforcement corrosion in the compressive zone of the RC sections.

By the end of discussion on few of past work given above concluding remark is given that there are many important structures like a historical building, Government building, hospitals, etc. All this old building needs to be strengthened to increase its durability so that it will be a long lasting until the end of service life. Various papers referred in this work are shown that till the date research is carried out in the field of service life is based upon the prediction of the ultimate value of shear force or bending moment, the prediction of appropriate cover thickness, analysis of area loss due to corrosion, but very less work is carried out in the field of remaining service life or how service life reduced or get influenced by corrosion. All the methods yet develop to find residual life are having mathematical models only, whereas the method developed in this work is a combination of the experimental and analytical work and proposed method is based up the NDT approach which further can be applied to find a residual life of existing building, and that is the major advantage of this method.

\section{Methodology}

The methodology presented in this work to estimate end of service life was divided into two parts. The first part of this proposed work consists of laboratory experiment to analyze changes in the behavior of a concrete specimen before and after corrosion through the dynamic parameter as a natural frequency. For this; beam specimen of size $150 \times 150 \times 500 \mathrm{~mm}$ was casted in the laboratory. Concrete beams were casted along with three different water to ce- 
ment ratio and two different covers to diameter ratio to do a simultaneous study on the effect of water to cement ratio and cover to diameter on the initiation and the propagation period of corrosion. The second part of this work consists of numerical analysis. For this FEM based Autodesk Algor simulation software was used. First natural frequency found by experimental work was further used to find equivalent Young's modulus $\left(E_{\text {equv }}\right)$ at different damage levels. The same beam casted in the laboratory is simulated in the software and iterations are made until and unless the first natural frequency of a simulated beam does not match with the experimental value of first natural frequency. Where all equivalent value of Young's modulus $\left(E_{\text {equv }}\right)$ at different level of damages were obtained simultaneously. Chloride attack penetration depth was calculated using Faraday's law of electrochemistry and at the end, the graphical representation of residual life was given. All the necessary steps taken to estimate the end of the functional life of the concrete beam specimen are summarized as follows in the next subsection.

\section{Experimental work}

\subsection{Test specimen characteristic}

To study the effect of reinforcement corrosion on RC structure; beam specimen of size $150 \times 150 \times 500 \mathrm{~mm}$ as shown in Figure 1 ( $\mathrm{a} \& \mathrm{~b}$ ) was selected with steel reinforcement of diameter $10 \mathrm{~mm}$ and $12 \mathrm{~mm}$. Concrete was designed with three different water to cement ratio, which are $0.45,0.55$ and 0.65 . The maximum size of aggregate used is $20 \mathrm{~mm}$ with $20 \mathrm{MPa}$ as a characteristic compressive strength of concrete. Three beam specimens of each water to cement ratio was casted which gives total 9 number of specimens with cover depth $20 \mathrm{~mm}$ and embedded steel reinforcement of $10 \mathrm{~mm}$ diameter. Another 9 specimens are casted with same concrete mix proportion, but with $12 \mathrm{~mm}$ diameter of embedded reinforcement and 40 $\mathrm{mm}$ cover depth as shown in Table 1.

All the casted specimens were demolded after 24 hours under laboratory condition and put into water curing tank until an age of 28 days as per IS 10262:2009. These casted specimens were used further to accelerate corrosion and the frequency was checked before and after the corrosion.

\subsection{Accelerated methods of corrosion}

Corrosion is a very slow process, even in the severe environment corrosion takes a very long time for the generation and propagation of corrosion by destabilizing passive layer generated during the hydration process of concrete (Sohail, Laurens, Deby, \& Balayssac, 2015).

The laboratory acceleration of corrosion is mainly consisting on the acceleration of the initiation phase and that causes the destabilization of the protective layer over steel and further corrosion achieved in a small time period (Liu et al., 2016; Otieno, Beushausen, \& Alexander, 2016). In this work impressed current technique was used by $5 \%$ concentrated $\mathrm{NaCl}$ as an electrolytic solution. The stainless steel rod was used as an anode and embedded reinforcement in beam specimen is used as a cathode. It was applied a constant voltage of $30 \mathrm{~V}$ with output current $3 \mathrm{~A}$ within the laboratory setup across the beam specimen as shown in Figure 2.

Once the corrosion process advances due to the electrochemical process of corrosion, rust starts to develop which much larger in a volume than existing reinforcement and get started to fill inside the pores of the concrete and developed radial pressure which further leads to cracking of concrete cover (Zhu, Francois, Fang, \& Zhang, 2016). To measure the penetration depth of chloride in concrete Faraday's law was used and presented by equation 1 (Alonso et al., 1998).

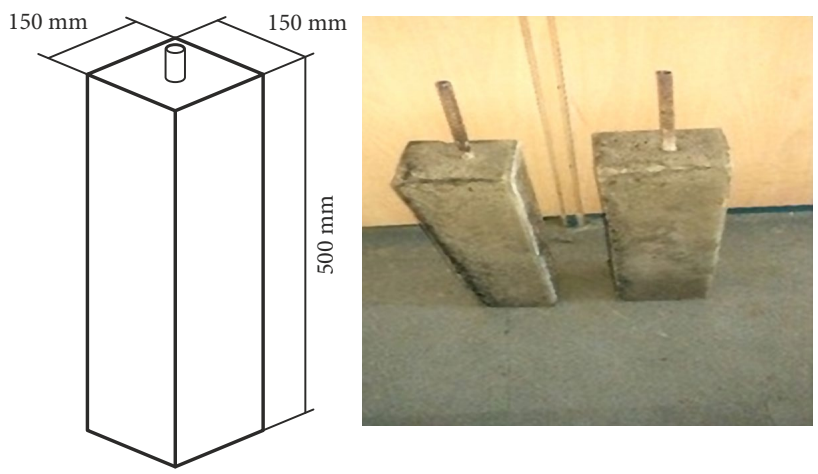

Figure 1. Beam specimen with dimension: a - Symmetrical representation of beam specimen; $b$ - Casted beam specimens as per the symmetry

Table 1. Mix proportion of concrete with three different water to cement ratio

\begin{tabular}{|l|c|c|c|}
\hline \multicolumn{1}{|c|}{ Mixture Type } & A10, A12 & B10, B12 & C10, C12 \\
\hline Water to cement ratio & 0.45 & 0.55 & 0.65 \\
\hline \multirow{2}{*}{ Reinforcement diameter } & A10 with $10 \mathrm{~mm}$ diameter & B10 with 10 mm diameter & C10 with 10 mm diameter \\
\cline { 2 - 4 } & A12 with $12 \mathrm{~mm}$ diameter & B12 with 12 mm diameter & C12 with 12 mm diameter \\
\hline Number of specimen & 3 of A10 and 3 of A12 & 3 of B10 and 3 of B12 & 3 of C10 and 3 of C12 \\
\hline Cement & 451 & 370 & 320 \\
\hline Fine Aggregate & 653 & 826.2 & 1254 \\
\hline Course Aggregate & 1153 & 1047.2 & 680 \\
\hline Water & 203 & 203 & 203 \\
\hline
\end{tabular}




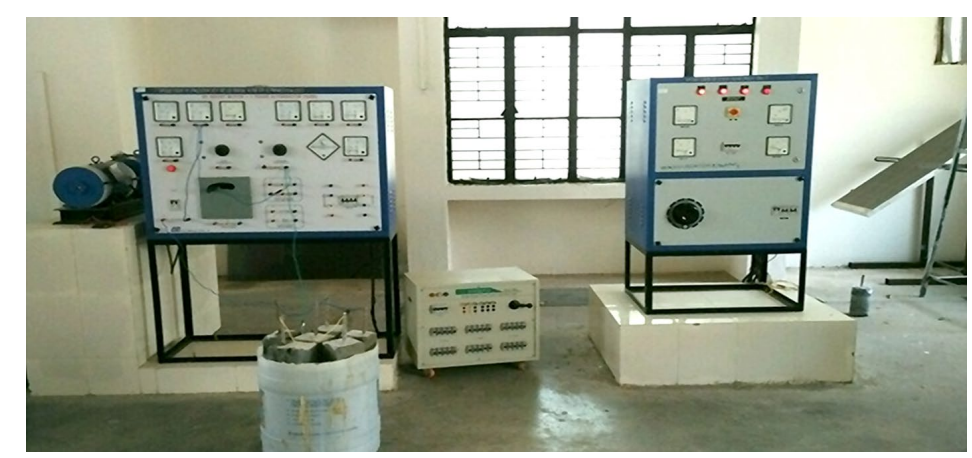

Figure 2. Laboratory setup of accelerated method of corrosion using impressed current technique

$$
P=0.32 \times I_{\text {corr }} \times t,
$$

where $P$ - Theoretical radius loss or bar penetration depth $(\mathrm{mm}) ; 0.032$ - Unit conversion factor $\left(\mathrm{mA} / \mathrm{cm}^{2}\right.$ to $\mathrm{mm} /$ day); $I_{\text {corr }}$ - Average value of current density $\left(\mathrm{mA} / \mathrm{cm}^{2}\right)$; $T$ - Time since the current was applied (days).

\subsection{Cracking and first natural frequency}

To analyze the behavior of beam before and after the corrosion dynamic parameter as the first natural frequency of the beam specimen was taken into consideration (Chopra, 1995). Rust formed due to corrosion exert radial pressure on the adjacent surface of the concrete and in response to this applied pressure crack starts to develop in the beam specimen. Cracking pattern of the beam was checked after every two days during accelerated method of corrosion using microscope graded with scale of precision $0.02 \mathrm{~mm}$ as shown in Figure $3(\mathrm{a} \& \mathrm{~b})$.

In order to determine the fundamental natural frequency electronic exciter was used. Beam specimens were kept over an exciter and in a central area of beam specimen piezoelectric accelerometer (sensitivity $102.1 \mathrm{mg} / \mathrm{g}$ ) was fixed which further connected to national instrument (NI 9234) and it passes the accelerometer signal to the spectrum analyzer as fast Fourier transfer (FFT), where lab view was used to determine frequency and amplitude corresponds to different measurements. Figure 4 shows lab setup to determine first natural frequency.

\section{Numerical model}

Numerical analysis was carried out using Autodesk Algor simulation software. In this work to find the effect of corrosion on the mechanical behavior of reinforced concrete beam specimen material property as equivalent Young's modulus $\left(E_{\text {equv }}\right)$ was taken into consideration. Therefore, to find this effect experimental value of first natural frequency was used and iterations were made in the software until the value of first natural frequency does not match with the experimental value. Further when it matches with the experimental value the corresponding value of equivalent Young's modulus was taken into consideration.

Total 6 types of the beam with three different water to cement ratio and two different covers to diameter ratio
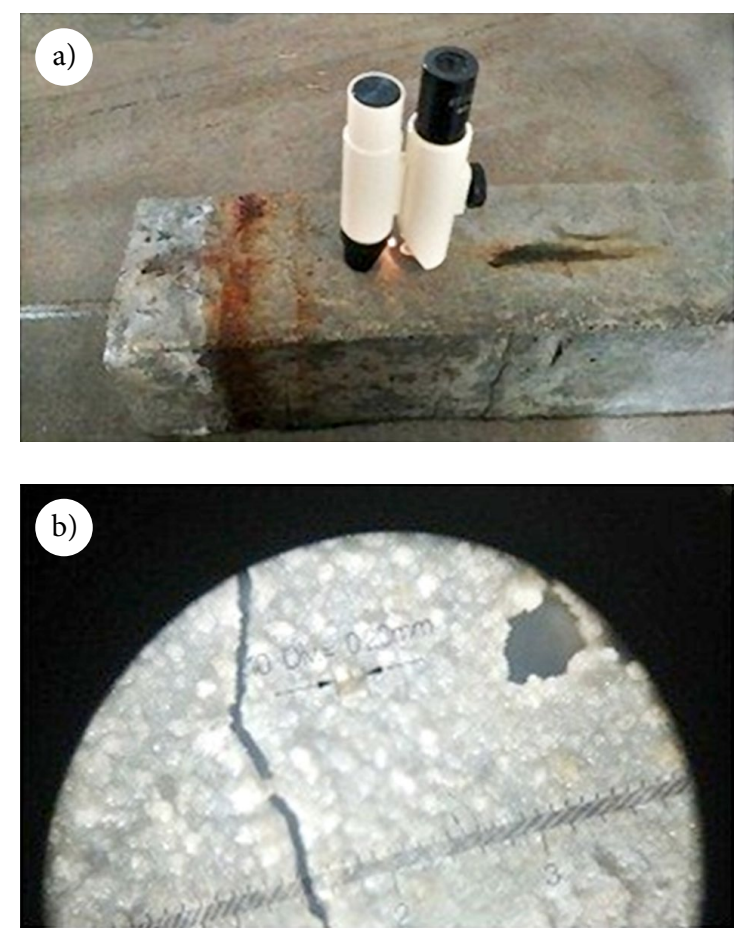

Figure 3. Beam crack measurement: a - Crack width measuring pocket microscope; $b$ - Crack width under microscope

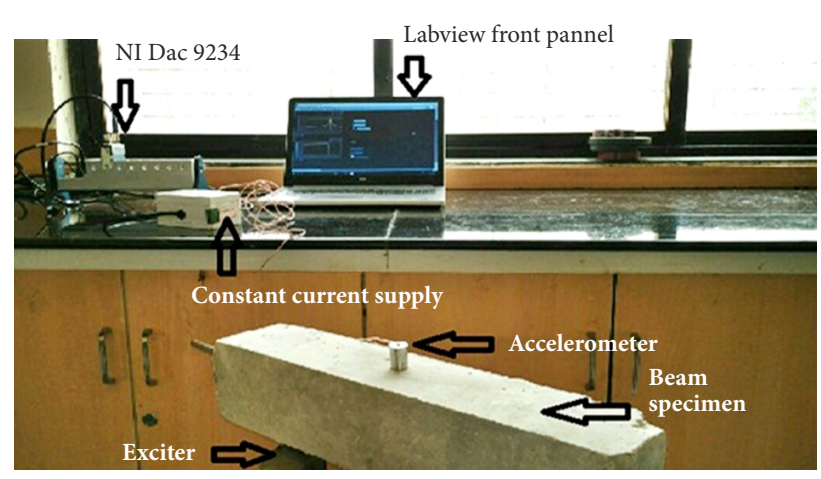

Figure 4. Laboratory setup to measure first natural frequency

were analyzed and experimental natural frequency was validated using Algor simulation software. A 3D model of the simply supported beam was built using brick elements and analyzed under no external load as shown in Figure 5. 


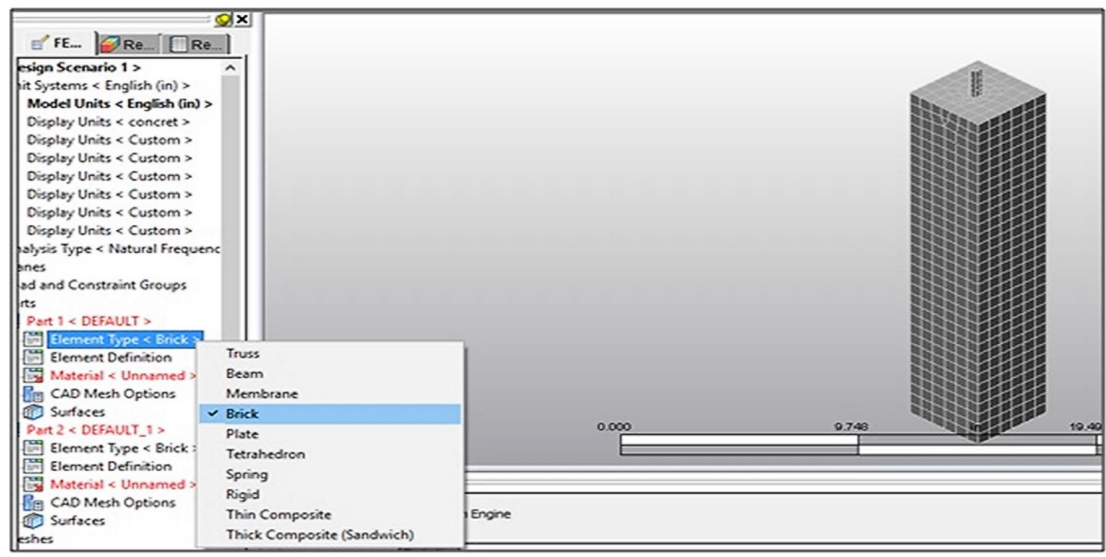

Figure 5. 3D beam specimen with meshing

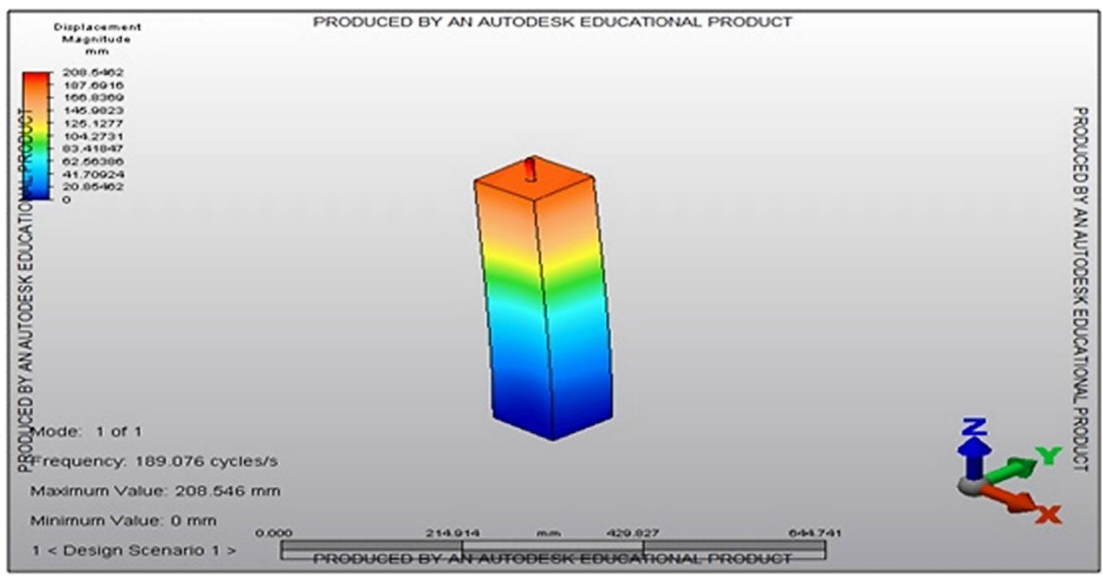

Figure 6. First natural frequency of beam A10

The reinforced concrete material was simulated as homogeneous and isotropic, with the following properties: Elasticity Modulus $=22360.67 \mathrm{MPa}$, Poissons ratio $=0.2$, Density $=2400 \mathrm{~kg} / \mathrm{m}^{3}$. Figure 6 gives a frequency result after applying material property and boundary condition.

Simulation work was conducted to analyze the influence of reinforcement corrosion on the behavior of reinforced concrete beam. For this four models are built again with the rectangular and triangular element and in order to simplify model in commercial software linear elastic analysis was conducted (Autodesk Algor Simulation Professional, 2012). The damaged zone was analyzed with equivalent Young's modulus $\left(E_{\text {equv }}\right)$ and damaged zone $E_{\text {equv }}$ value was adjusted until first natural frequency coincides with the experimental value of the different damaged level. Subsequently, the graph was plotted between $E_{\text {equv }}$ and chloride attack penetration depth as shown in Figure 7.

\section{Results and discussion}

Acceleration of corrosion is conducted in the laboratory until the formation of the first crack into a beam specimen and in this experiment cracking area of the corroded beam specimen, time to accelerate corrosion and first

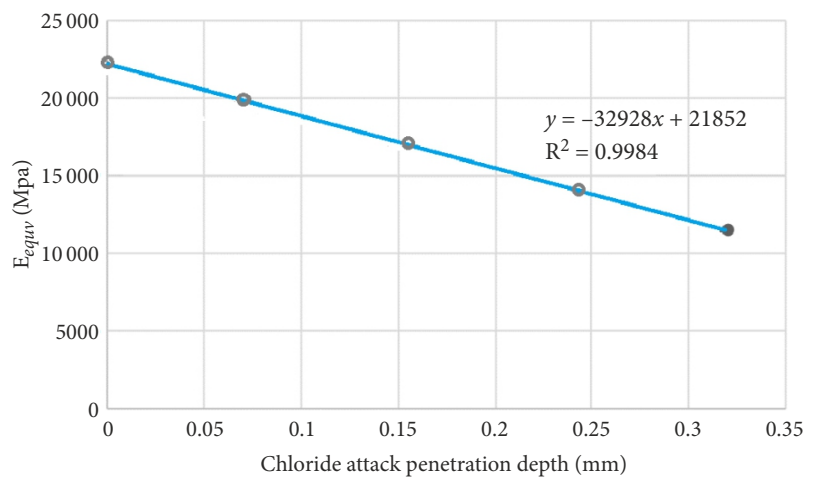

Figure 7. Variation of Eequv and chloride attack penetration depth

natural frequency parameters are studied simultaneously. Table 2 gives the first natural frequency of 18 beam specimen before and after corrosion. The compressive strength is found out from casted cubes of size $15 \times 15 \times 15 \mathrm{~cm}$. From Table 2 it seems that the first natural frequency of all 18 non-corroded beams is almost same even though all these 18 beam specimens are cast with three different water to cement ratio and 2 different diameters to cover ratio. This can be explained as the first natural frequency is directly proportional the square root of the modulus of elasticity 
Table 2. Frequency loss of beam specimen after corrosion

\begin{tabular}{|c|c|c|c|}
\hline \multirow{2}{*}{ Beam type } & \multirow{2}{*}{$\begin{array}{c}\text { Compressive } \\
\text { strength } \\
(\mathrm{kN})\end{array}$} & \multicolumn{2}{|c|}{ First natural frequency } \\
\cline { 3 - 4 } & & $\begin{array}{c}\text { Initial first natural } \\
\text { frequency }(\mathrm{Hz})\end{array}$ & $\begin{array}{c}\text { Frequency } \\
\text { loss }\end{array}$ \\
\hline $\mathrm{A} 10$ & 22.3 & 186.4 & $12.00 \%$ \\
\hline $\mathrm{A} 12$ & 22.4 & 187.2 & $11.00 \%$ \\
\hline $\mathrm{B} 10$ & 22 & 185 & $14.00 \%$ \\
\hline $\mathrm{B} 12$ & 22.1 & 186.5 & $14.50 \%$ \\
\hline $\mathrm{C} 10$ & 21.5 & 184 & $16.40 \%$ \\
\hline $\mathrm{C} 12$ & 21.7 & 184.8 & $17.00 \%$ \\
\hline
\end{tabular}

multiplied by the moment of inertia and inversely proportional to mass. For this reason, the strength of concrete does not meaningfully affect the first natural frequency wherein opposite direction modulus of elasticity and moment of inertia shows the effect on the first natural frequency.

Table 2 also shows frequency loss of beam specimen after corrosion and it is noticed that due to corrosion 11\% to $17 \%$ frequency loss is occurring and loss in first natural frequency is mainly related to cracking area and penetration depth of chloride in concrete. The effect of corrosion on the modal parameter and they had a test on beam specimens similar those used in this work and reported that, there is a $4 \%$ reduction in the first natural frequency with a loss of the bar section of about $8 \%$. After analyzing first natural frequency loss parametric study is carried out and the graph is plotted. The first graph is assigning between first natural frequency and time to accelerate corrosion as shown in Figure 8. The second graph is assigning between first natural frequency versus cracking area as shown in Figure 9. The cracking area is determined by the product of length times the width of each crack, measured using a pocket microscope on the concrete surface.

From Figure 8 it is noticed that as the corrosion advances first natural frequency decreases similarly in all the beams with little dispersion, whereas in case of cracking area it increases with increase in test time period of accelerated corrosion. C. Alonso et al. (1998) studied all those factors which affects on cracking of concrete due to corrosion and from this paper it is observed that the cracking of concrete due corrosion is not only control by the cover depth of concrete but there are number of another factor like quality of concrete, water to cement ratio and efficiency of current which equally contribute in process of corrosion cracking. A considerable amount of dispersion is occurring in the first natural frequency and cracking area after the end of 14 days of the accelerated corrosion experiment.

Figure 9 gives that, with the end of accelerated corrosion testing cracking area of all the beam specimens are ranges between 50 to $200 \mathrm{~mm}^{2}$. The cracking areas of all the beams are different and this takes place due to different water to cement ratio of all the three different design mix a)

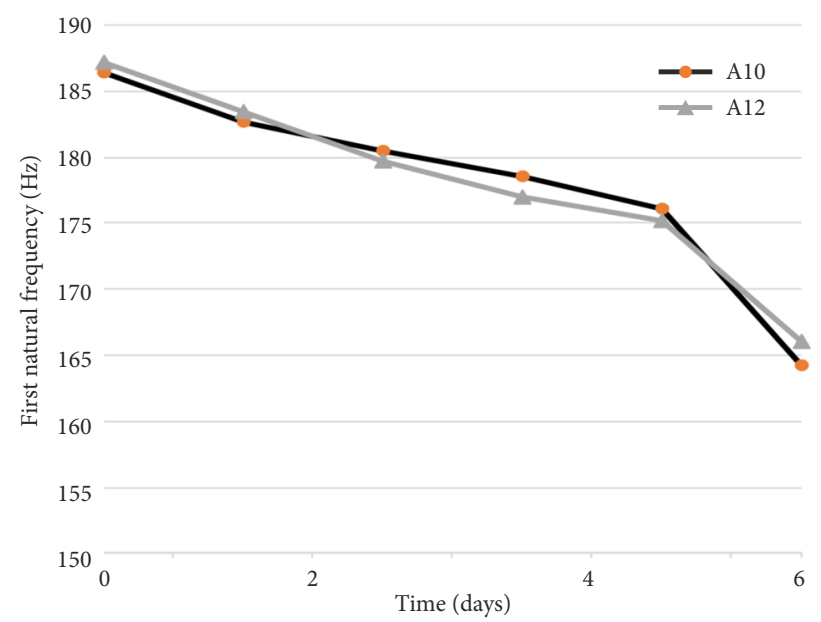

b)

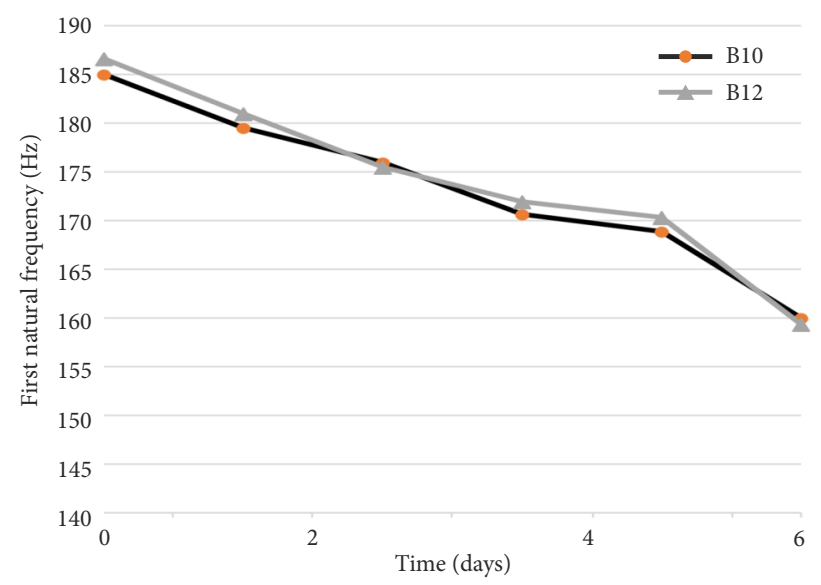

c)

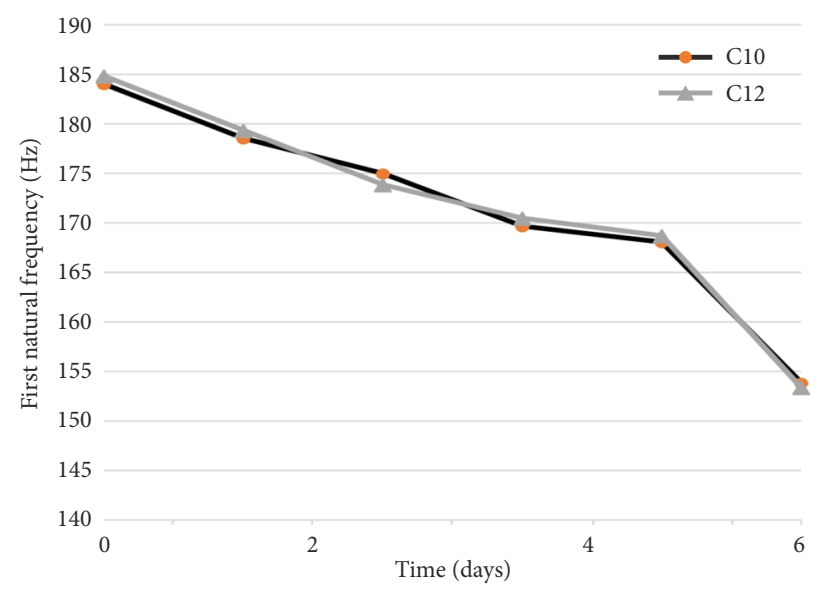

Figure 8. Variation of first natural frequency $(\mathrm{Hz})$ versus test time (days): a - First natural frequency vs test time (Beam A10 and A12); b - First natural frequency vs test time (Beam B10 and B12); c - First natural frequency vs test time (Beam C10 and $\mathrm{C} 12$ )

used for the beam specimens. For example, cracking area of beam A10 and A12 is $50 \mathrm{~mm}^{2}, 60 \mathrm{~mm}^{2}$ respectively, whereas, in beam specimen C10, C12 areas are $110 \mathrm{~mm}^{2}$ and $120 \mathrm{~mm}^{2}$ respectively this variation in cracking area take place due to the pore structure of concrete. In beam 
A10, A12 water to cement ratio is 0.45 whereas in beam specimen C10, C12 it is 0.65 and due to increase in water to cement ratio concrete become porous and cracking area increases.

At the end of the experiment, all three basic parameters taken under consideration are studied simultaneously using 3D graph plotted within first natural frequency, cracking area and time period of accelerated corrosion

a)

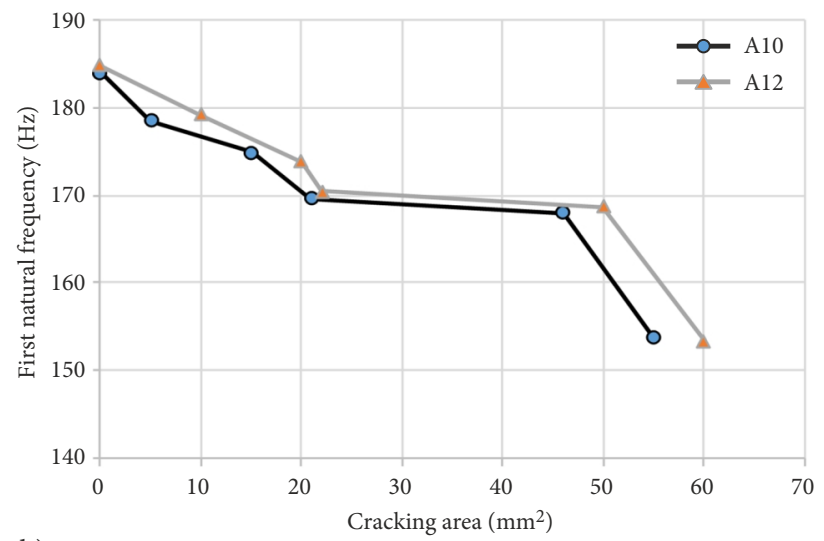

b)

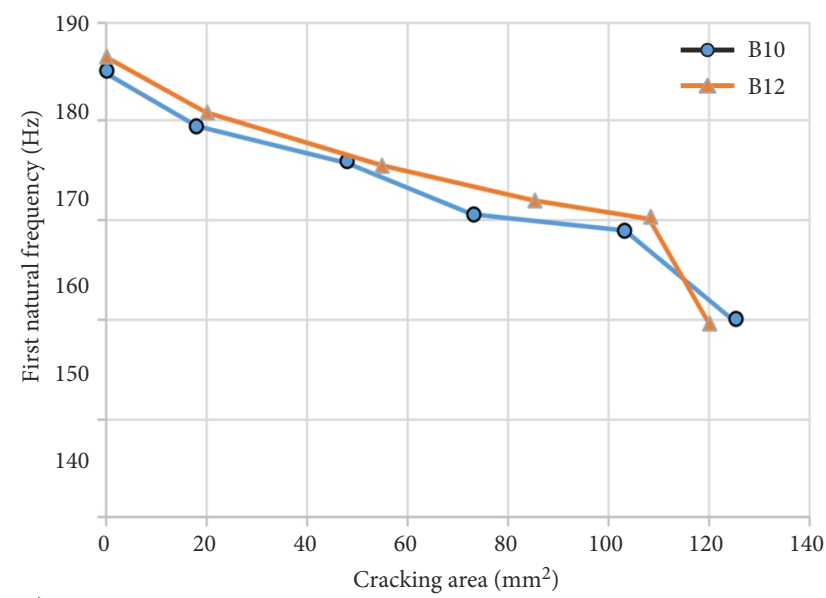

c)

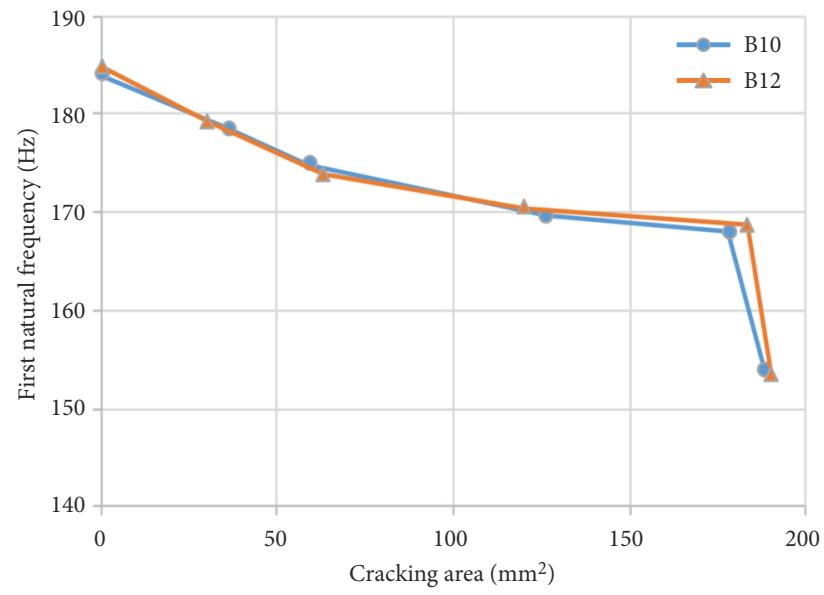

Figure 9. Natural frequency $(\mathrm{Hz})$ versus cracking area $\left(\mathrm{mm}^{2}\right)$ : a - First natural frequency vs cracking area of beam A10, A12; b - First natural frequency vs cracking area of beam B10, B12; c - First natural frequency vs cracking area of beam C10, C12 testing as shown in Figure 10. From this graph, it is clear that first natural frequency decreases with increase in test time of corrosion acceleration and cracking area (Tapan \& Aboutaha, 2011). Where a variation in first natural frequency of beam specimen is similar and progresses with a little desperation until there is no cover loss and reduction in moment of inertia of beam specimen and similar observations are given by M. Fayyadh, H. Razak and Z. Ismail (2011), R. Kandasamya et al. (2016).

After the study of all the parameters by accelerated methods of corrosion and natural frequency analysis further study is conducted to give a graphical representation of residual life as follows.

It is worth to mention that chloride attack penetration depth measured using Faraday's law of electrochemistry is given by equation 1. Finally, Figure 11 gives the graphical representation of the residual life. In this graph life is represented by means of three axes out of these three one axes in my direction gives $E_{\text {equv }}$ and out of the other

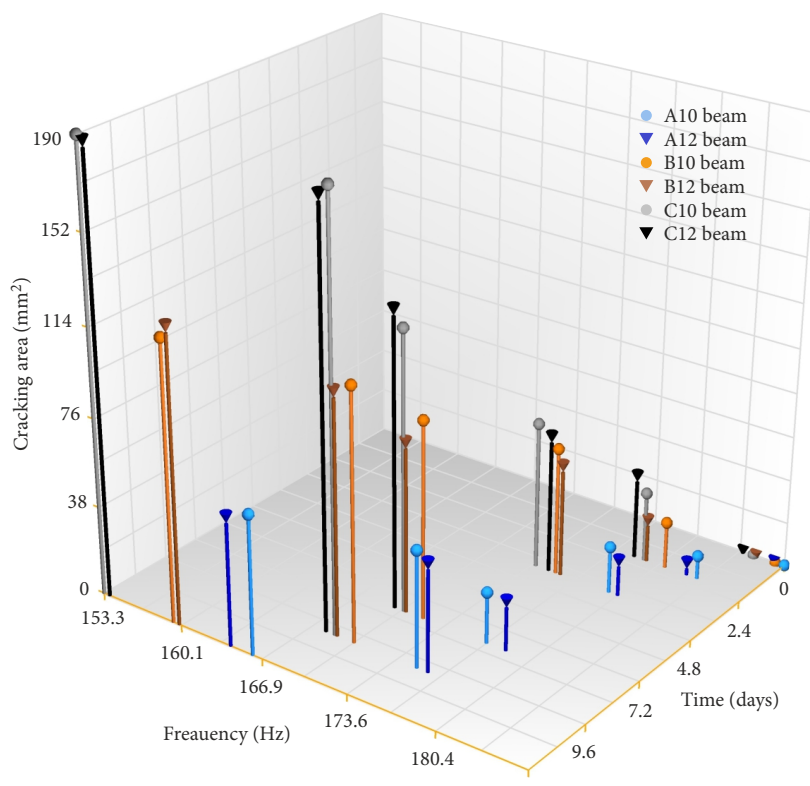

Figure 10. 3D graph for first natural frequency, cracking area, test time of accelerated corrosion

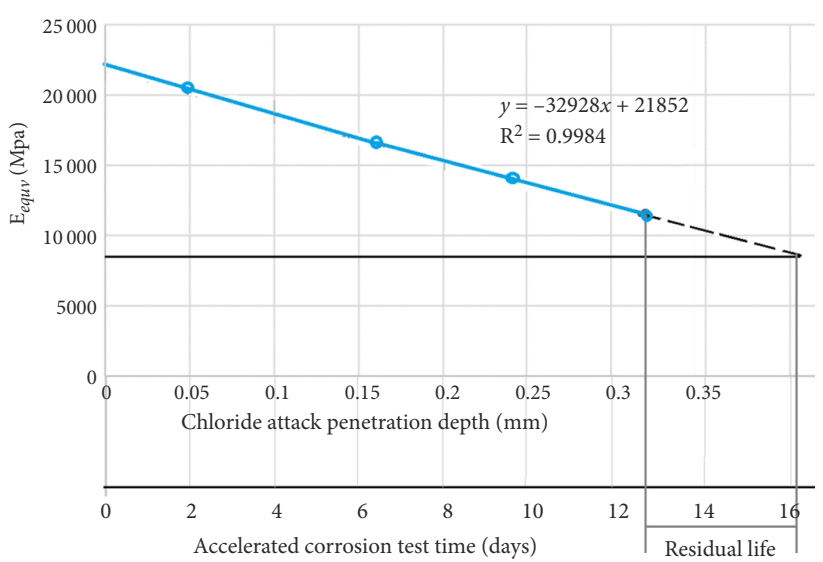

Figure 11. Graphical representation of residual life 
two axes, one represents attack penetration depth and second represent test time of corrosion acceleration in days. From the graph it is concluded that the attack penetration depth is linearly proportional to $E_{\text {equv }}$ and where to get further results in this graph values are extrapolated using $\mathrm{MEF}$ and limiting value of natural frequency is given by CEB 209 (1991), American Institute of Steel Construction (1997), DIN 4150 (1999).

\section{Conclusions}

In this work, the influence of reinforcement corrosion is studied using dynamic parameters as first natural frequency. From the experimental and numerical analysis conducted in this work, the following conclusions are provided.

1. Two different covers to depth ratio are provided for this study and from this variation in the cover to the depth ratio, it is observed that as the cover increases, there is an increase in initiation time period for the corrosion. Whereas after the arrival of the first crack there was no impact of cover depth as there was an equal corrosion rate in the cracked specimen with $20 \mathrm{~mm}$ and $40 \mathrm{~mm}$ cover depth.

2. Slow corrosion rate $\left(I_{\text {corr }}\right)$ in the acceleration of corrosion shows the early initiation of cracking in the beam specimen instead of that if we increase the corrosion rate it seems that time required on arrival of the first crack is increased. Increase in water to cement ratio increases permeability of concrete, which lead to increase in initiation time for corrosion where on the other hand the time required to propagate corrosion is getting reduced. To accelerate corrosion within a laboratory number of methods are available but all these methods do not simulate corrosion process as exactly as it occurs in the real environment.

3. There is linear proportion of first natural frequency and chloride attack penetration depth. First natural frequency is proportional to the moment of inertia of the structure and there is no impact observed due to variation in water to cement ratio and strength of beam specimen instead of that first natural frequencies propagate with a little desperation until there is no change in the moment of inertia due to corrosion. The increase in chloride attack penetration depth results in to decrease in $E_{\text {equv }}$. It states that corrosion results in degradation of the material property of concrete. At the end of experimental and analytical results, residual life of concrete is graphically represented.

4. This method gives the effect of corrosion on dynamic behavior and mechanical property of a structure, therefore, it can be possible to implement this method for structural analysis and residual life prediction.

\section{References}

Ahmad, S. (2003). Reinforcement corrosion in concrete structures, its monitoring and service life prediction - a review. Cement \& Concrete Composites, 25, 459-471.

https://doi.org/10.1016/S0958-9465(02)00086-0

American Institute of Steel Construction. (1997). Floor vibrations due to human activity. Chicago.

Autodesk Algor Simulation Professional. (2012). Professional Mech/VE, Docutech, Linear Stress and Dynamics, Autodesk, Inc.

Alonso, C., Andradel, C., Rodriguez, J., \& Dies, J. M. (1998). Factors controlling cracking of concrete affected by reinforcement corrosion. Materials and Structures, 31, 435-44. https://doi.org/10.1007/BF02480466

Aveldano, R., \& Ortega, N. (2009). Influence of reinforcement distribution in the corrosive process of reinforced concrete beams. Magazine of Concrete Research, 61(3), 213-220. https://doi.org/10.1680/macr.2008.00013

Capozucca, R., \& Nilde Cerri, M. (2003). Influence of reinforcement corrosion in the compressive zone on the behaviour of RC beams. Engineering Structures, 25, 1575-1583. https://doi.org/10.1016/S0141-0296(03)00119-6

Capozucca, R. (1995). Damage to reinforced concrete due to reinforcement corrosion. Construction and Building Materials, 9(5), 295-303. https://doi.org/10.1016/0950-0618(95)00033-C

Chopra, A. K. (1995). Dynamics of structures: theory and applications to earthquake engineering. New Jersey: Prentice Hall.

CEB 209. (1991). Vibration Problems in Structures - Practical Guidelines.

DIN 4150. (1999). Part 3, Structural Vibration in Buildings, Effects of Vibration on Structures, German Standard, DeutschesInstitut Fur Normung EV.

Fayyadh, M., Razak, H., Ismail, Z. (2011). Combined modal parameters-based index for damage identification in a beamlike structure: theoretical development and verification. Archives Civil and Mechanical Engineering, 11(3), 587-609.

https://doi.org/10.1016/S1644-9665(12)60103-4

IS 10262:2009. Indian standard, concrete mix proportioning guideline.

Khan, I., Franois, R., \& Castel, A. (2014). Prediction of reinforcement corrosion using corrosion induced crack width in corroded reinforced concrete beams. Cement and Concrete Research, 56, 84-96.

https://doi.org/10.1016/j.cemconres.2013.11.006

Kandasamya, R., Cuia, F., Townsendb, N., Chiang, C., Guoa, J., Snob, A., \& Xiongb, Y. (2016). A review of vibration control methods for marine, offshore structures. Ocean Engineering, 127, 279-297. https://doi.org/10.1016/j.oceaneng.2016.10.001

Liu, M., Cheng, X., Lia, X., Hu, J., Pan, Y., \& Jin, Z. (2016). Indoor accelerated corrosion test and marine field test of corrosionresistant, low-alloy steel rebars. Case Studies in Construction Materials, 5, 87-99.

https://doi.org/10.1016/j.cscm.2016.09.005

Otieno, M., Beushausen, H., \& Alexander, M. (2016). Chlorideinduced corrosion of steel in cracked concrete - Part I: Experimental studies under accelerated and natural marine environments. Cement and Concrete Research, 79, 373-385. https://doi.org/10.1016/j.cemconres.2015.08.009

Ortega, N., \& Robles, S. (2016). Assessment of residual life of concrete structures affected by reinforcement corrosion. HBRC Journal, 12, 114-122.

https://doi.org/10.1016/j.hbrcj.2014.11.003 
Palumbo, N. (1991). Accelerated corrosion testing of steel reinforcement in concrete. Thesis report submitted to the department of civil engineering and applied mechanics Mcgill university, Canada.

Razak, H., \& Choi, F. (2001). The effect of corrosion on the natural Frequency and modal damping of reinforced concrete beams. Engineering Structures, 23(9), 1126-1133. https://doi.org/10.1016/S0141-0296(01)00005-0

Sohail, M. G., Laurens, S., Deby, F., \& Balayssac, J. P. (2015). Significance of macrocellcorrosion of reinforcing steel in partially carbonated concrete: numerical and experimental investigation. Materials and Structures, 48(1), 217-233. https://doi.org/10.1617/s11527-013-0178-2

Torres-Luque, M., Bastidas-Arteaga, E., Schoefs, F., SanchezSilva, M., Osma, J. F. (2014). Non-destructive methods for measuring chloride ingress into concrete: state-of-the-art and future challenges. Construction and building materials, 68, 6881. https://doi.org/10.1016/j.conbuildmat.2014.06.009
Tapan, M., \& Aboutaha R. (2011). Effect of steel corrosion and loss of concrete cover of strength of deteriorated RC columns. Construction and Building Materials, 25, 2596-2603. https://doi.org/10.1016/j.conbuildmat.2010.12.003

Wang, X., Zhang, W., Gu, X., \& Dai, H. (2013). Determination of residual cross-sectional areas of corroded bars in reinforced concrete structure using easy to measure variables. Construction \& Building Materials, 38, 846-853.

https://doi.org/10.1016/j.conbuildmat.2012.09.060

Zhu, W., Francois, R., Fang, Q., \& Zhang, D. (2016). A Influence of long-term chloride diffusion in concrete and the resulting corrosion of reinforcement on the serviceability of RC beams. Cement and Concrete Composites, 71, 144-152. https://doi.org/10.1016/j.cemconcomp.2016.05.003

Zhu, W., \& Francois, R. (2014). Corrosion of reinforcement and its influence on the residual structural performance of 26-year-old corroded RC beam. Construction \& Building Materials, 51, 461-472.

https://doi.org/10.1016/j.conbuildmat.2013.11.015 